\title{
Oncolytic Viral Therapy of Malignant Glioma
}

\author{
Jacqueline Nuss Parker,* David F. Bauer, ${ }^{\dagger}$ James J. Cody,* and James M. Markert ${ }^{\dagger}$ \\ *Department of Pediatrics, Division of Infectious Diseases, ${ }^{\dagger}$ Department of Surgery, Division of Neurosurgery, University of \\ Alabama at Birmingham, Birmingham, Alabama 35294
}

Summary: Novel approaches to treatment of malignant glioma, the most frequently occurring primary brain tumor, have included the use of a wide range of oncolytic viral vectors. These vectors, either naturally tumor-selective, or engineered as such, have shown promise in the handful of phase I and phase II clinical trials conducted in recent years. The strategies developed for each of the different viruses currently being studied and the history of their development are summarized here. In addition, the results of clinical trials in patients and their implication for future trials are also discussed. Key Words: Oncolytic viral therapy, malignant glioma, G207, HSV 1716, ONYX-015 adenovirus, Reolysin, vaccinia, Newcastle disease virus, measles virus.

\section{INTRODUCTION}

Malignant glioma is the most frequently occurring primary brain tumor. Prognosis is abysmal, despite surgical resection and chemotherapy/radiation therapy, with time to progression averaging 6 months and median survival of one year. Investigations into the use of oncolytic viruses (OVs) for the treatment of a variety of malignancies, including malignant glioma, were initiated more than half a century ago after anecdotal observations that some cancer patients experienced periods of remission after suffering from an acute illness of viral etiology, or after being inoculated with attenuated viral vaccines. Perhaps the most well-known case report came from de Pace in 1912 that described a patient whose cervical carcinoma regressed after receiving Pasteur's attenuated rabies vaccine strain after a dog bite. ${ }^{1}$ Subsequently, adenoviruses (earlier referred to as adenoidal-pharyngeal-conjunctival, or APC viruses) were inoculated in 30 patients with epidermoid cervical carcinomas. ${ }^{2}$ In this study, $65 \%$ of treated tumors had areas of necrosis after intratumoral inoculation. Naturally-occurring viruses evaluated for the treatment of acute leukemia include Newcastle disease virus, Sendai, Semliki forest virus and influenza viruses. ${ }^{3}$ Cases of Burkitt's lymphoma ${ }^{4}$ and Hodgkin's disease ${ }^{5}$ have partially responded to treatment with the measles virus. In the late 1970s, the mumps

Address correspondence and reprint requests to: James M. Markert, M.D., M.P.H. FOT 1060, University of Alabama at Birmingham, Birmingham, AL 35294-3410. E-mail: jmarkert@uabmc.edu. virus was administered for various human cancers, with one study enrolling 200 patients. ${ }^{6,7}$

Until the early 1990s, safety concerns limited the use of these nonattenuated, replication-competent viruses as primary anti-tumor therapy. Instead, replication-defective viruses, including engineered adenovirus and retrovirus vectors, were evaluated as gene therapy vectors for cancer therapy. However, numerous problems were associated with these vectors, including adequate virus delivery and distribution, insufficient levels of both gene transfer and gene expression, and lack of prolonged efficacy. More recently, advancements in molecular biology, combined with research in novel experimental therapies for cancer treatment has renewed interest in applying OVs for glioma therapy. A history of these advancements with respect to CNS malignancies, and a summary of the different OVs under evaluation, is provided.

There are numerous advantages of oncolytic virotherapy. First, if not already naturally discriminating, OVs can be genetically engineered to be selective for mitotically active, neoplastic cells. This is especially appealing for glioma therapy, as the tumor-adjacent, quiescent neurons remain resistant and intact after treatment. Second, most of the viruses discussed herein, and all those tested in phase I clinical trials for malignant glioma thus far, are replication-competent in addition to being oncolytic. This means that tumor killing is not limited to the initial target cell. Rather, its tumor-targeted cytolytic advantage can spread to surrounding cells that escaped initial infection. This latter property theoreti- 
cally allows for OVs to seek out and destroy tumor cells distal from the initial treatment site. Third, some OVs have large genomes enabling the introduction of one or more foreign genes, allowing them to act as gene therapy vectors for augmentation of the antitumor effect. M002 (discussed as follows) is one example of an oncolytic herpes simplex virus (HSV) engineered for expression of murine interleukin (IL)-12 heterodimers specifically in tumor cells only. Finally, any viruses that demonstrate efficacy in the treatment of brain tumors can be used clinically in combination with standard treatment modalities.

\section{History of oncolytic viral therapy}

In 1991, Martuza et al. ${ }^{8}$ reported that the engineered HSV thymidine kinase-deleted mutant, $d l$ sptk, was replication-attenuated in nondividing cells, such as neurons. The $t k$ gene deletion required the virus to rely on mitotically active cells to supply both thymidine kinase and nucleotide pools for DNA replication. The $d l$ sptk virus displayed a promising therapeutic profile in the treatment of glioma in animal studies. However, the tk gene inactivation also rendered this mutant resistant to antiviral agents, such as acyclovir, which targets the viral thymidine kinase. Lost susceptibility to the viral tk-targeted drugs, combined with an undesirable toxicity level at high titers, prevented advancement of this OV into clinical trials for malignant glioma. Nevertheless, these "proof of concept" studies led to the development of the first generation of clinically safe HSV vectors, G207, and HSV1716, as described in more detail as follows.

As with any novel therapy, safety after administration in humans is the highest priority, but in addition, OVs must demonstrate potent anti-tumor activity either alone or combined with existing standard therapies, such as de-bulking surgery, radiation, and chemotherapy. During the past 2 decades, a number of promising OVs have been developed that have demonstrated anti-glioma activity in preclinical studies. These include polio virusderived vectors, vaccinia virus, Newcastle disease virus, and most recently, measles virus vectors. In addition, phase I clinical trials have been completed for several OVs, including HSV-1 (G207 and HSV1716), ${ }^{9,10}$ a conditionally replicative adenovirus (CRAd) termed Onyx015, ${ }^{11}$ and a reovirus, REOLYSIN (Oncolytics Biotech Inc, Calgary, Ontario, Canada). ${ }^{12} \mathrm{~A}$ number of these vectors have already demonstrated their safety after administration in patients, including some in combination with prior debulking surgery or in combination with radiation. ${ }^{13,14}$ Yet, major hurdles remain, which includes efficient delivery of OVs, both into the primary tumor mass, as well as delivery to tumor cells distal from the primary site; tumor-specific genotypes resistant to certain OV therapies; and persistence of viral replication and expression of foreign genes introduced to augment
OV activity by multiple mechanisms. Strategies to overcome these hurdles are currently under intense investigation and will be discussed at the end of this review.

\section{HERPES SIMPLEX VIRUS-1}

Herpes simplex virus type 1 (HSV-1) is a well-studied, neurotropic virus with essential and nonessential genes that have been established. ${ }^{15}$ The genes involved in its oncolytic properties are distinct from the genes for neurovirulence, and manipulation of the viral genome allows continued oncolysis with conditional replication in cancer cells. Its sensitivity to acyclovir and ganciclovir gives HSV a distinct advantage over other oncolytic vectors in that it adds to its safety profile when used in human clinical trials.

After the development of HSV-1 virus dlsptk as previously described, other HSV vectors have been constructed that are avirulent in the normal brain, but can proliferate in actively cycling cells due to different mutations. HSV-1 mutant hrR3 contains an inactivating lac $Z$ insertion into the $\mathrm{U}_{\mathrm{L}} 39$ locus encoding the large subunit of ribonucleotide reductase (infected cell protein $6),{ }^{16}$ required for the synthesis of nucleotides in a postmitotic cellular environment, such as neurons, which would otherwise not support HSV proliferation. The $\mathrm{U}_{\mathrm{L}} 39$ mutation is complemented in trans ${ }^{17}$ via the cellular version of the enzyme in malignant gliomas and other cycling cells, such that hrR3 can still infect these rapidly dividing cells. ${ }^{18}$ In addition, this mutation increases susceptibility of the virus to anti-viral therapy with acyclovir and ganciclovir. ${ }^{19}$

Because of its large genome ( $>150 \mathrm{~kb}$ ), up to $30 \mathrm{kbp}$ of HSV genome can be replaced with foreign DNA while still retaining the ability of the virus to replicate. After infection with wild-type HSV-1, double stranded RNA is produced, and this RNA is sensed by protein kinase $\mathrm{R}$ (PKR) through an intracellular stress response. PKR phosphorylates eukaryotic initiation factor alpha (eIF$2 \alpha$ ), which turns off protein synthesis. Expression of infected cell protein 34.5 , a gamma-1 gene, leads to dephosphorylation of eukaryotic initiation factor alpha (eIF-2 $\alpha$ ), restoring protein synthesis. Infected cell protein 34.5 is expressed from the $\gamma_{1} 34.5$ gene, which is present in two copies and located in the inverted repeat regions flanking the unique long segment of the viral genome. Restoration of protein synthesis occurs when infected cell protein 34.5 recruits protein phosphatase1a, leading to eukaryotic initiation factor alpha (eIF-2 $\alpha$ ) dephosphorylation. ${ }^{20}$ R3616, constructed by Chou et al., ${ }^{21}$ lacks both copies of the $\gamma_{1} 34.5$ gene and was derived from the wild-type virus, HSV-1 (F) strain. Deletion or disruption of both copies of the $\gamma_{1} 34.5$ gene severely limits virus replication, unless its target is a tumor cell that possesses a complementing mutation, 
such as ras overexpression, ${ }^{22}$ or alterations in PKR and other cell-signaling pathways. ${ }^{23}$ Deletion of this gene also removes part of the latency-activated transcripts, which are encoded on the complementary antisense DNA strands. As such, these viruses are impaired in their ability to establish latency after infection. ${ }^{24}$ R3616 was the parent virus for G207, which has now completed two phase 1 clinical trials in the United States. Results of a third trial are pending.

\section{Herpes simplex viruses: clinical trials}

The first generation oncolytic herpes simplex virus vectors (OHSV) that have already completed phase 1 or early phase 2 clinical trials in patients have one or both of these attenuating mutations $\left(\gamma_{1} 34.5\right.$ deletion and $\mathrm{U}_{\mathrm{L}} 39$ disruption). G207, developed by Mineta et al.' $\mathrm{s}^{25}$ group, combined both of these strategies and was constructed on HSV-1 (F) wild-type background. HSV1716, in contrast, only lacks copies of its $\gamma_{1} 34.5$ gene- the UL39 sequences remain intact. HSV1716 is derived from wild-type strain 17 and was constructed by MacLean et al. ${ }^{26}$

G207. G207 has deletions of both copies of its $\gamma_{1} 34.5$ gene in addition to a lac $Z$ insertion into the $\mathrm{U}_{\mathrm{L}} 39$ locus. ${ }^{25}$ These two mutations improve the safety of G207 by rendering it susceptible to standard anti-HSV therapy, and by impairing ability of the virus to establish latency within an infected cell. Preclinical studies demonstrated that G207 was safe in neurotoxicity studies in mice and nonhuman primates, and efficacious against the U87 human malignant glioma xenograft model in immunocompromised mice. ${ }^{27}$ New World owl monkeys (Aotus nancymae) were used for the primate neurotoxicity studies due to their exquisite sensitivity to HSV infection. ${ }^{28}$ These monkeys showed no clinical signs of HSV-induced illness after G207 inoculation (up to $1 \times 10^{9}$ plaque forming units [PFU] of G207 injected).

Three phase I trials have been completed to date for G207 treatment alone or in combination with radiation. In the initial trial, a total of 21 subjects were enrolled, all of whom had recurrence of tumor diagnosed on CT or MRI after standard therapy (resection or biopsy followed by radiation). Each patient received a stereotactic intratumoral injection of G207 within the enhancing portion of the tumor, starting at a dose of $1 \times 10^{6} \mathrm{PFU}$ in the first cohort, $1 \times 10^{7}$ PFU in the second cohort, and a dose escalation in half-log increments for each subsequent cohort (three patients per cohort). A maximally tolerated dose could not be established; even at the highest dose $\left(3 \times 10^{9} \mathrm{PFU}\right)$. CT scans 30 days after virus inoculation showed reduced enhancement in eight patients, with eight patients who survived 9 or more months posttreatment, and a single glioblastoma multiforme (GBM) patient remained alive 5.5 years after inoculation without evidence of disease. ${ }^{9}$
The objectives of the second phase Ib G207 trial were three-fold: 1) to confirm the safety and tolerability of intratumoral inoculation of G207, as well as inoculation into the brain surrounding the tumor; 2) to demonstrate active replication inside the tumor; and 3) to demonstrate the safety of multiple-dose delivery of the virus. Six patients with recurrent GBM were enrolled in the study. A catheter was stereotactically implanted into the tumor, and $13 \%$ of a total dose of $1.15 \times 10^{9} \mathrm{PFU}$ of G207 was injected through the catheter. Either 2 or 5 days later, the tumor was resected en bloc with the catheter in place, and the remainder of the G207 was injected into the tumor bed. Radiological and pathological evidence of anti-tumor activity was seen. Evidence of HSV replication in situ was demonstrated. HSV encephalitis did not develop in any patient, although one patient experienced transient fever, delirium, and hemiparesis, which entirely resolved within 12 hours on high-dose dexamethasone; no acyclovir was necessary. These symptoms were attributed to inadvertent inoculation of the virus into the ventricular system. Overall, G207 appeared to be safe both for multiple-dose delivery and for direct inoculation into the brain surrounding the tumor cavity. ${ }^{13}$

HSV1716. Concurrent with the G207 studies in the United States, HSV1716, derived from HSV strain 17, was being tested in clinical trials in Glasgow, United Kingdom. Like G207, HSV1716 also lacks both copies of the $\gamma_{1} 34.5$ gene, but its UL39 gene remains intact. ${ }^{26}$ In the initial HSV1716 phase I trial, nine patients (eight GBM and one AA) who had all undergone prior surgery and radiotherapy, with most who had received chemotherapy, had an initial dose of $1 \times 10^{3}$ PFU stereotactically inoculated into the enhancing portion of the tumor. This dose was increased by $1 \log$ in each of three cohorts, with three patients per cohort, ending at a maximum dose of $1 \times 10^{5} \mathrm{PFU}$. At the highest dose, no signs of encephalitis or other dose-limiting toxicities were encountered, and no maximally tolerated dose was reached. ${ }^{10}$

To validate safety and demonstrate in situ viral replication, a second phase I trial was conducted. In this trial, 12 patients ( $11 \mathrm{GBM}$ and $1 \mathrm{AA})$ received $1 \times 10^{6} \mathrm{PFU}$ of HSV1716 via direct intratumoral inoculation prior to surgical resection 4 to 9 days later. Again, this virus was proven safe and replication within the tumor was supported by PCR detection of the virus in two of the resected tumors. ${ }^{14}$

Recently, according to their website, Crusade Laboratories has received regulatory approval to begin Europewide phase III clinical trials of HSV1716 in glioma patients after first recurrence postresection and radiotherapy, with satisfactory results potentially leading to license and marketing authorization for glioma therapy.

M002/M032. OHSV engineered to express transgenes (including interleukins, such as IL-4 or IL-12) have been shown to enhance tumor killing in both syn- 
geneic murine brain tumor models and human glioma xenograft tumor models. ${ }^{29,30}$ M002 and M032, like G207, are both derived from HSV-1 (F) strain with deletion of both $\gamma_{1} 34.5$ gene copies, but in contrast, the UL39 gene remains intact in M002 and M032. A bicistronic expression cassette encoding IL-12 p40 and p35 subunits from either murine (M002) or human (M032) origin, and separated by an internal ribosome entry sequence (IRES), were introduced into both 34.5 deleted sites. $^{30}$ A lot of M032 has been produced using current good manufacturing practices through the National Cancer Institute Rapid Access to Intervention Development program for eventual use in phase I clinical trials in humans.

Next generation HSV. A number of different strategies are currently being used to enhance anti-tumor potential of OHSV vectors. These include introduction of foreign genes for pro-drug conversion, ${ }^{31-33}$ tumor-specific gene expression, ${ }^{34,35}$ and expression of other viral proteins that restore efficient viral replication, ${ }^{36,37}$ to name a few. Genetic manipulation of HSV proteins that mediate virus entry, combined with new discoveries related to the mechanism of tumor cell resistance to OHSV therapies have led to the engineering of novel tumortargeted HSV vectors. For example, an OHSV was constructed to specifically target the IL-13R $\alpha 2$ receptor, ${ }^{38}$ found abundantly on high-grade astrocytomas, but not on normal human tissues. ${ }^{39}$ Derivatives of this IL13Ra2targeted virus have been constructed, which are no longer capable of binding to the normal HSV entry receptor, nectin $1 .^{40,41}$ Other tumor-targeting strategies under investigation for OHSV vectors include the use of tumor-specific promoters $^{35,42,43}$ or radiation-inducible promoters ${ }^{44}$ for the expression of genes that optimize the tumor cell microenvironment for efficient viral replication.

Malignant gliomas will likely require a broad approach that incorporates current treatment strategies with novel therapeutics, including OHSV. Dual treatment regimens combining OHSV therapy with ionizing radiation or chemotherapies are all strategies currently under intensive investigation. ${ }^{45-49}$

In summary, the G207 and HSV1716 clinical trials reinforce the safety and potential benefit that OHSV vectors may offer to patients with malignant glioma.

\section{CONDITIONALLY REPLICATING ADENOVIRUSES (CRAds)}

Human adenovirus serotype 5 (Ad5) has served as the platform for a multitude of oncolytic viral agents. This nonenveloped DNA virus is not associated with any serious disease and has a well-characterized genome of approximately $36 \mathrm{~kb}$ that allows for relatively easy manipulation. ${ }^{50}$ Recent years have witnessed a rapid expansion in the number of strategies with CRAds intended to treat glioma, illustrating the variety of strategies by which this might be accomplished. An overview of the CRAds that have been developed, as well as those that have advanced or those that will soon be advanced to clinical trials, is summarized as follows.

\section{ONYX-015}

ONYX-015 is an adenovirus made conditionally replicative by deletion of the E1B-55k gene, which is responsible for binding cellular p53. This interaction normally prevents apoptosis of the infected cell, permitting continued viral replication. Although this CRAd was intended to replicate selectively within p53-deficient cells, it has since been shown that other functions of E1B-55k are responsible for its cancer-selective replication. ${ }^{51}$ ONYX-015 was among the first CRAds to be described and has been utilized in clinical trials for head and neck cancer. More recently, human glioma xenografts were shown to be susceptible to ONYX-015 replication in vivo, ${ }^{52}$ an effect that was enhanced by radiation therapy ${ }^{53}$ These findings led to a phase I clinical trial for recurrent glioma, in which ONYX-015 was administered to the tumor bed after surgical resection. The virus was well-tolerated in this trial, with no evidence of toxicity. However, efficacy was not determined. ${ }^{11}$

\section{Ad- $\Delta 24$ and derivatives}

Other partial deletions of the Ad5 genome have also been used to generate CRAds. Fueyo et al. ${ }^{54}$ described a CRAd in which the E1A gene was partially deleted. This CRAd (designated as Ad- $\Delta 24$ ) has a 24-base pair deletion within E1A that renders the protein unable to bind cellular $\mathrm{Rb}$, thus limiting its replication to cells with disregulated cell cycles. Ad- $\Delta 24$ was more oncolytic than an E1B-deleted CRAd in a panel of glioma cell lines tested, and was more effective in suppressing tumor growth in both intracranial and subcutaneous models of glioma. ${ }^{55}$ In addition, because Ad- $\Delta 24$ increases expression and activity of topoisomerase I in glioma cells, its antitumor effect was shown to be synergistically improved in an experimental murine glioma model when administered along with the topoisomerase I inhibitor irinotecan. ${ }^{56}$

The Ad- $\Delta 24$ system has itself served as the platform for a number of modifications, including the addition of transgenes whose expression should augment its oncolytic potency. Some examples include $\mathrm{p} 53,{ }^{57,58}$ a humanized form of the pro-drug converting enzyme yeast cytosine deaminase, ${ }^{59}$ and the tissue inhibitor of matrix metalloproteinase- $3 .{ }^{60}$

Other modifications of Ad- $\Delta 24$ vectors have focused on the fiber knob to target glioma-specific receptors. Adenovirus infection depends on initial binding of the knob portion of the fiber capsid protein with the coxsackievirus and adenovirus receptor on the cell surface, followed by a secondary binding of Arg-Gly-Asp (RGD) 
motifs in the viral capsid to cell surface integrins. Many tumor cell types, including gliomas, express low levels of coxsackievirus and adenovirus receptor, but high levels of integrins. Inclusion of an RGD peptide in the fiber knob retargets initial binding of the virus to cell surface integrins. ${ }^{61}$ In addition, Ad- $\Delta 24-R G D$ can infect glioma stem cells isolated from human tumor specimens and can induce autophagy in these cells. ${ }^{62}$

Finally, the Ad- $\Delta 24$ system has also been modified by those seeking to enhance the selectivity of its replication. This has been achieved either by deletion of additional portions of the genome, ${ }^{55,63,64}$ or by the addition of exogenous promoters, such as the $\mathrm{E} 2 \mathrm{~F} 1^{65}$ and tyrosinase promoter. $^{66}$

\section{CRAd-survivin}

The CRAd-survivin system includes several oncolytic adenoviruses, in which replication is controlled by the survivin promoter. ${ }^{67-72}$ Survivin is an inhibitor of apoptosis protein, which is normally active only during embryogenesis. These survivin-controlled CRAds have incorporated a number of different fiber genes to enhance their infection of glioma cells. Examples include RGDmodified fiber, ${ }^{72}$ a chimeric fiber with $\mathrm{Ad} 3 \mathrm{knob}^{69}$ and the inclusion of a poly-lysine motif. ${ }^{70}$ In addition, the activity of the survivin promoter is induced by radiation, thereby increasing viral replication and resulting in a synergistic antitumor effect when virus administration is combined with radiation therapy. ${ }^{67}$

\section{Oncolytic adenoviruses-additional therapeutic strategies}

In addition to the three systems previously detailed, a variety of other strategies for the generation of gliomatargeted CRAds have also been described. Bieler et al. ${ }^{73}$ used an adenovirus with a partial deletion of E1A in combination with irinotecan and trichostatin A (a histone deacetylase inhibitor that upregulates coxsackievirus and adenovirus receptor expression) in a three-pronged strategy to improve replication and destroy drug-resistant glioma cells. This virus also acts synergistically to inhibit tumor growth in vivo when used in conjunction with radiation. ${ }^{74}$ Other groups have developed CRAds for which replication was dependent upon a hypoxia response element, ${ }^{75}$ the glial fibrillary acidic protein promoter ${ }^{76}$ or the hTERT promoter. ${ }^{77,78}$ Hoffmann et al. ${ }^{79,80}$ constructed a CRAd with the E1A and E4 genes under control of the glial fibrillary acidic protein and Ki67 promoters, respectively.

In some cases, CRAds have been infectivity-enhanced through the inclusion of an RGD-modified fiber ${ }^{78}$ or a chimeric fiber consisting of the Ad5 fiber tail and the Ad35 shaft and knob (referred to as 5/35), which retargets the virus to CD46. ${ }^{79-81}$ Several of these CRAds have demonstrated enhanced antitumor activity when administered with chemotherapeutic agents, such as temozolomide, ${ }^{78,80}$ RAD001, ${ }^{78}$ and carmustine. ${ }^{75}$ Finally, inclusion of cytotoxic transgenes, such as thymidine kinase ${ }^{82}$ or TRAIL ${ }^{81}$ in CRAds has also been investigated.

Ongoing studies with CRAd vector systems continue to investigate the optimal combination of viral mutations with standard therapies for glioma therapy. Table 1 summarizes all of the CRAd vectors described herein.

\section{REOVIRUS}

Reoviruses are nonenveloped RNA viruses that usually do not cause serious disease, but they may be associated with very mild gastrointestinal or respiratory symptoms that can resolve without further incidence. ${ }^{83}$ As discussed earlier in this review, under normal cellular conditions after viral infection, the PKR pathway is activated as a result of the intracellular double-stranded RNA that is produced. PKR activation results in host protein synthesis shutoff, and consequently in viral replication. In many tumor cells, activation of this pathway is blocked in cells in which the Ras signaling pathway has been upregulated via $\mathrm{EGFR}^{84}$ and PDGFR ${ }^{85}$ mutations commonly found in malignant gliomas, which permits productive infection of reoviruses. The naturally discriminatory phenotype of reovirus for cells with unrestrained Ras pathway activity, combined with its mild disease profile in humans led to its evaluation as an $\mathrm{OV}$ for therapy of multiple tumor types, including glioma. Early studies showed that of the multiple brain tumors specimens tested ex vivo for vulnerability to reovirus, all glioma specimens were killed, as well as 20 of 24 glioma cell culture lines, but none of the meningiomas tested were susceptible. ${ }^{86}$ Experimental models of glioma using $\mathrm{U} 87$ and $\mathrm{U} 251 \mathrm{~N}$ cell lines in vitro and in vivo demonstrated the efficacy of reovirus and confirmed its natural limitation to neoplastic cells. ${ }^{87}$ However, serious toxicity involving severe hind limb necrosis at the injection site, myocarditis, and eventual virus-mediated death, if administered intracranially, occurred in immunocompromised severe combined immunodeficiency (SCID) mice treated with reovirus. Such toxicity has not been seen in other, non-SCID models. ${ }^{87,88}$ Although immunocompromised by their tumor and glucocorticoid use, toxicity in otherwise immune competent cancer patients was predicted to be minimal due to the known mild disease profile of reovirus in humans. After direct inoculation in primates, no significant toxicities were observed, ${ }^{89}$ paving the way for phase 1 trials in patients. Two phase I dose escalation trials, in which reovirus (Reolysin) was injected intratumorally in patients suffering from recurrent malignant glioma, have been conducted in Canada (University of Calgary) and in the United States (University of Alabama at Birmingham, Ohio State University, and Cedars-Sinai Medical Center). ${ }^{12}$ The second 
Table 1. Oncolytic Adenoviruses for Glioma Therapy

\begin{tabular}{|c|c|c|c|c|c|}
\hline Agent & Replication Control & $\begin{array}{l}\text { Infection } \\
\text { Control }\end{array}$ & Receptor Target & $\begin{array}{l}\text { Transgene: } \\
\text { Promoter }\end{array}$ & Location \\
\hline ONYX-015 & $\Delta \mathrm{E} 1 \mathrm{~B}-55 \mathrm{k}$ & None (wt fiber) & CAR & & \\
\hline Ad $-\Delta 24^{54}$ & $\Delta 24$ & None (wt fiber) & CAR & & \\
\hline Ad- $\Delta 24-p 53^{57}$ & $\Delta 24$ & None (wt fiber) & CAR & p53: SVE & E3 \\
\hline Ad- $\Delta 24-h y C D^{59}$ & $\Delta 24$ & None (wt fiber) & CAR & hyCD: CMVi.e. & E3 \\
\hline Ad- $\Delta 24-$ TIMP $^{60}$ & $\Delta 24$ & None (wt fiber) & CAR & TIMP3:CMVi.e. & E3 \\
\hline Ad- $\Delta 24-$ RGD $^{61}$ & $\Delta 24$ & RGD fiber & $\begin{array}{l}\alpha \mathrm{v} \beta 3, \alpha \mathrm{v} \beta 5 \\
\quad \text { integrins, CAR }\end{array}$ & & \\
\hline $\mathrm{CB} 1^{63}$ & $\Delta 24, \Delta \mathrm{E} 1 \mathrm{~B}-55 \mathrm{k}$ & None (wt fiber) & CAR & & \\
\hline Ad- $\Delta 24 / 39^{55}$ & $\Delta 24, \Delta 39$ & None (wt fiber) & CAR & & \\
\hline $\mathrm{Ad}-2 / 24 \mathrm{CMV}^{64}$ & $\mathrm{CMV}, \Delta 2, \Delta 24$ & None (wt fiber) & CAR & & \\
\hline ICOVIR- $5^{65}$ & $\mathrm{E} 2 \mathrm{~F} 1, \Delta 24$ & RGD fiber & $\begin{array}{l}\alpha \mathrm{v} \beta 3, \alpha \mathrm{v} \beta 5 \\
\text { integrins, CAR }\end{array}$ & & \\
\hline Ad-24TYR ${ }^{66}$ & Tyrosinase, $\Delta 24$ & None (wt fiber) & CAR & & \\
\hline Ad-24CMV 64 & $\mathrm{CMV}, \Delta 24$ & None (wt fiber) & CAR & & \\
\hline CRAd-survivin-RGD ${ }^{72}$ & Survivin & RGD fiber & $\begin{array}{l}\alpha \mathrm{v} \beta 3, \alpha \mathrm{v} \beta 5 \\
\quad \text { integrins, CAR }\end{array}$ & & \\
\hline CRAd-survivin- $5 / 3^{69}$ & Survivin & $\begin{array}{l}\text { 5/3 Chimeric } \\
\text { fiber }\end{array}$ & $\begin{array}{l}\text { CD } 46, \text { CD } 80, \\
\text { CD86 }\end{array}$ & & \\
\hline CRAd-survivin-pk ${ }^{70}$ & Survivin & pk7 fiber & HSPG & & \\
\hline $\mathrm{d} 1520^{73}$ & Del. of E1A $13 \mathrm{~S}$ & None (wt fiber) & CAR & & \\
\hline HYPR-Ad ${ }^{75}$ & Hypoxia response element & None (wt fiber) & CAR & & \\
\hline Ad5-gfa2(B)3-E1 ${ }^{76}$ & GFAP with $B$ enhancer & None (wt fiber) & CAR & & \\
\hline hTERT-Ad $^{77}$ & hTERT & None (wt fiber) & CAR & EGFP:nativeE1B & E1 \\
\hline hTERT-Ad-RGD ${ }^{78}$ & hTERT & RGD fiber & $\begin{array}{l}\alpha \mathrm{v} \beta 3, \alpha \mathrm{v} \beta 5 \\
\quad \text { integrins, CAR }\end{array}$ & EGFP:nativeE1B & E1 \\
\hline $\mathrm{Ad} 5 / 35 . \mathrm{G} \Delta \cdot \mathrm{ki}^{79}$ & GFAP (E1A), Ki67 (E4) & $\begin{array}{l}5 / 35 \text { Chimeric } \\
\text { fiber }\end{array}$ & CD46 & & \\
\hline Ad5/Ad35.IR-E1A/TRAIL ${ }^{81}$ & Inverted repeats, RSV & $\begin{array}{l}\text { 5/35 Chimeric } \\
\text { fiber }\end{array}$ & CD46 & $\begin{array}{l}\text { TRAIL:IRS, } \\
\text { RSV }\end{array}$ & E1 \\
\hline IG.Ad5.E1+.E3TK ${ }^{82}$ & NA (wild-type) & None (wt fiber) & CAR & hsvTK:nativeE3 & E3 \\
\hline
\end{tabular}

$\mathrm{wt}=$ wild type.

study is still underway at the time of this writing. In the Calgary study, up to $1 \times 10^{9} \mathrm{PFU}$ of virus was administered in the highest dose group, which was well tolerated. No maximally tolerated dose was defined in this study. These results warrant continued investigation of reovirus in efficacy studies alone or in combination with currently defined standard of care therapies, including radiation and chemotherapy.

\section{PARAMYXOVIRUS}

\section{Newcastle disease virus}

The avian paramyxovirus, Newcastle disease virus (NDV), is a highly contagious disease of chickens, turkeys, and many wild birds. On occasions of human infection, NDV can cause cause mild flu-like symptoms, laryngitis, and conjunctivitis. ${ }^{90}$ Although both the lytic and nonlytic strains can be cytotoxic, ${ }^{91}$ it is the lytic strains that have been more extensively investigated as anti-neoplastic agents after the virus was found to show enhanced replication efficiency in cancer cells as compared with replication in normal cells. ${ }^{92,93}$ The NDV vector 73-T was one of the early vectors to show efficacy in a number of animal tumor models after direct administration into human neuroblastoma ${ }^{94}$ and fibrosarcoma ${ }^{95}$ xenografts in mice. Efficacy was also demonstrated after intraperitoneal administration for treatment of a variety of carcinomas. ${ }^{96}$ Another NDV attenuated vector, PV 701, has been tested in several solid tumors, but not tumors of CNS origin, for safety after intravenous administration using different dosing regimens. ${ }^{97-99}$

Two NDV strains have been evaluated in early phase I/II clinical trials of patients with recurrent GBM: MTH68/H and NDV-HUJ. The MTH-68/H NDV strain has been utilized by a Hungarian group for the treatment of a number of cancers. ${ }^{100-102}$ In 1999 , a case was reported of a 14 year-old boy diagnosed with a recurrent GBM who was treated intravenously with MTH-68/H daily, beginning in April 1996. ${ }^{101}$ The tumor reportedly shrunk between November 1996 and September 1998, after which chemotherapy was discontinued, and at last report the boy had been receiving only MTH-68/H injections. In 2004, four additional case studies using MTH-68/H in one adult and three pediatric GBM patients were reported with substantial increase survival rates ranging 
between 5 and 9 years. ${ }^{103}$ Finally, MTH-68/H therapy combined with valproic acid (an antiepileptic drug, also shown to have anti-tumor activity) was evaluated in a pediatric patient with anaplastic astrocytoma unresponsive to irradiation and chemotherapy. ${ }^{104}$

The most recent NDV vector to be assessed in a phase I/II clinical trial of recurrent GBM is the lentogenic NDV strain HUJ. ${ }^{105}$ Lentogenic NDV strains cause mild or asymptomatic illness in poultry that is limited to the respiratory tract. The NDV vectors previously described (73-T, PV701 and MTH-68H) are all mesogenic strains (moderately pathogenic), and use of these strains poses increased the risk of undesirable side effects. The safety and anti-tumor activity of the lentogenic NDV-HUJ vector was assessed after intravenous administration of multiple doses. A total of 14 patients, including one pediatric patient, were enrolled. All patients had MRI confirmed recurrent GBM. No major side effects were observed, and one patient had a complete tumor response. Although replication of the HUJ strain is limited in humans, infectious particles were recovered for up to 9 days after dosing in the patients, and suggests that limited replication is occurring, possibly in the tumor tissue. Further studies are warranted using this attenuated strain.

Another NDV vector being developed deserves discussion here. Zulkifli et al. ${ }^{106}$ evaluated the V4UPM strain, a modified V4 strain, which developed as a thermostable feed pellet vaccine for poultry for oncolytic activity against two glioma cell lines (DBTRG.05MG and U-87MG), both in vitro and in vivo in subcutaneous flank tumors. The U-87MG was very susceptible to V4UPM, both in vitro and in vivo after a single virus dose. The DBTRG.05MG cell line was more resistant to the NDV vector, but oncolysis still occurred. When a single intratumoral administration to the latter tumors did not result in regression, a second higher dose of virus was administered. Despite this, the tumor grew persistently, although the overall tumor volume was significantly reduced as compared to the control treatment group alone.

\section{Measles virus}

Another member of the Paramyxoviridae family, measles virus (MV) represents a fairly recent addition to the growing panel of oncolytic viral vectors being evaluated for glioma therapy. The MV receptor, CD46, is upregulated in many glioma cell lines, allowing for preferential tumor targeting. ${ }^{107,108}$ The measles virus vector MVcarcinoembryonic antigen (CEA), engineered to overexpress the human carcinoembryonic antigen, has demonstrated infection of a number of human glioma cell lines and xenografts. ${ }^{108}$ Toxicology studies using MV-CEA in rhesus monkeys, including MRI imaging 4 to 5 months after direct intracranial administration, demonstrated no evidence of neurological dysfunction. ${ }^{109}$ The authors indicated that a phase I study to test the safety of MV-
CEA, after administration both intratumorally and into the resection bed, is underway.

\section{POXVIRUSES}

\section{Vaccinia virus}

Vaccinia virus, a member of the Poxviridae family, has been recently considered for use as an oncolytic vector for glioma therapy, in part due to results from a phase III trial in patients with stage III melanoma. ${ }^{110}$ Administered as a tumor vaccine, a polyvalent vaccinia melanoma oncolysate revealed an increase in the disease-free interval and overall survival in treated patients. Similar to the initial thymidine kinase deletion mutants in HSV-1, tk inactivation in vaccinia virus limits replication to transformed cells. ${ }^{111,112} \mathrm{~A}$ recombinant vaccinia virus engineered to express p53 (rVV-p53) was demonstrated to inhibit growth of a number of human and murine glioma cell lines alone ${ }^{113}$ or in combination with radiation therapy in the rat C6 glioma model. ${ }^{114}$ Recombinant VV that express IL-2 or IL-12 have enhanced viralmediated oncolysis as compared with viruses that do not express one of these cytokines. ${ }^{115,116}$

\section{Myxoma virus}

Another poxviridae family member being considered for oncolytic viral therapy is the myxoma virus, with tropism that is restricted to European rabbits. The myxoma virus is nonpathogenic in humans. ${ }^{117}$ The myxoma viruses has been shown to have oncolytic activity against a number of human glioma and medulloblastoma cell lines in vitro and increased tumor reduction in vivo. ${ }^{118,119}$ Combination of intratumoral injection of myxoma virus with rapamycin treatment increased intratumoral viral replication and prolonged survival of tumor-bearing mice. ${ }^{119}$ The oncolytic activity of the myxoma virus in syngeneic tumors in immunocompetent animals remains to be determined.

\section{POLIOVIRUS}

\section{Recombinant PV: PV-RIPO}

The neuropathogenicity of poliovirus (PV) can be attenuated by mutations within the IRES sequence located in the $5^{\prime}$ untranslated region of its genome. ${ }^{120}$ Substitution of the PV-1 Mahoney IRES sequence with the IRES sequence from human rhinovirus type 2 was described to severely attenuate it while maintaining its ability to replicate in non-neuronal cells. ${ }^{120}$ This mutant, referred to as PV-1-RIPO, was demonstrated to be safe for intracranial administration. ${ }^{121,122} \mathrm{PV}$ recombinants such as PV1-RIPO are naturally tropic for GBM due to expression of the poliovirus receptor CD155 on these tumors. ${ }^{122,123}$ Subsequently, PVS-RIPO (derived from the Sabin vac- 
cine strain, not the wild type PV-1 Mahoney strain) was shown to be genetically stable after in vivo passage in GBM xenografts, alleviating concerns regarding its phenotypic stability in the context of its replication in malignant glioma. This finding, supported by lack of sequence changes after serial passage, ${ }^{124}$ supports consideration of PVS-RIPO for advancement into clinical trials in patients with recurrent GBM.

\section{Poliovirus-derived replicons}

Replicons are oncolytic poliovirus derivatives, engineered with a deletion in the capsid (P1) protein, which prevents release of new infectious particles after a single replication cycle. ${ }^{125,126}$ Safety was established using transgenic mice expressing the human poliovirus receptor that were given both wild-type polio virus to compare to replicon administration both intracranially and intraspinally. ${ }^{127}$ Replicons have demonstrated oncolytic activity in a number of CNS-derived tumors in vitro, ${ }^{128}$ as well as increased survival of SCID mice bearing intracranial tumors of the human malignant glioma cell line, known as D54-MG.

\section{RHABDOVIRUS}

\section{Vesicular stomatitis virus}

Vesicular stomatitis virus (VSV) is part of the Rhabdoviridae family, which are negative-sense, nonsegmented RNA viruses with a genetic organization that is similar to the Paramyxoviridae family, both of which are part of the Mononegavirales order. VSV infection in humans is rare, and usually asymptomatic in those cases. ${ }^{129}$ When compared as one of nine potential new OVs for glioma therapy, the VSV variant, termed VSV-rp30, was superior to the other candidates regarding replication, spread, and ability to lyse tumor cells. ${ }^{130}$ This virus was selected for adaptation to optimal replication in malignant glioma cells after numerous serial passages. A recent report showed that intravenous administration of VSV-rp30 in experimental murine models of both human and mouse intracranial tumors specifically targeted those tumors, as compared to control viruses which did not. Tumors outside the brain were also targeted by VSVrp30, suggesting that this virus may be an effective target against migrating tumor cells as well. ${ }^{131}$

Table 2. Summary of Oncolytic Viruses in Glioma Clinical Therapy Pipeline

\begin{tabular}{|c|c|c|c|c|}
\hline Virus & Name & Tumor-targeting Mutation(s) & Clinical Trial Status & References \\
\hline \multirow[t]{3}{*}{ HSV-1 } & G207 & $\begin{array}{l}\gamma_{1} 34.5 \text { genes deleted, lac } Z \\
\text { insertion in UL39 }\end{array}$ & $\begin{array}{l}\text { Two Phase I studies complete; } \\
\text { phase II trial with IR } \\
\text { underway }\end{array}$ & 9,13 \\
\hline & HSV-1716 & $\gamma_{1} 34.5$ genes deleted & $\begin{array}{l}\text { Phase I/II studies complete; } \\
\text { phase III in planning stages }\end{array}$ & 10,14 \\
\hline & M032 & $\begin{array}{l}\gamma_{1} 34.5 \text { genes deleted, } \\
\text { human(M032) IL-12 } \\
\text { transgene inserted }\end{array}$ & Phase I planning stage & 30 \\
\hline \multirow[t]{2}{*}{ Adenovirus } & ONYX-015 & E1B-55kD deleted & Phase I & 11 \\
\hline & Ad- $\Delta 24-R G D$ & $\begin{array}{l}24 \text { bp deletion in E1A/RGD } \\
\text { fiber }\end{array}$ & Phase I in progress & 61 \\
\hline Reovirus & Reolysin & Naturally tumor-selective & Phase $\mathrm{I}$ in progress & \\
\hline \multirow[t]{3}{*}{ Newcastle disease virus } & МTH-68/H & $\begin{array}{l}\text { Attenuated NDV strain } \\
\text { (mesogenic) }\end{array}$ & Pilot phase I & $101-104$ \\
\hline & NDV-HUJ & $\begin{array}{l}\text { Attenuated NDV strain } \\
\text { (lentogenic) }\end{array}$ & Phase I & 105 \\
\hline & V4UPM & Attenuated NDV strain & Preclinical & 106 \\
\hline Measles virus & MV-CEA & $\begin{array}{l}\text { Overexpresses human } \\
\text { carcino-embryonic antigen }\end{array}$ & Phase I trial underway & 109 \\
\hline Vaccinia virus & rVV-p53 & p53 gene insertion & Preclinical & 113,114 \\
\hline Myxoma virus & & Naturally tumor-selective & Preclinical & 119 \\
\hline Polio virus & PV-RIPO & $\begin{array}{l}\text { Native IRES substituted with } \\
\text { IRES from human } \\
\text { rhinovirus type } 2\end{array}$ & Preclinical & 121,122 \\
\hline Vesicular stomatitis virus & VSV-rp30 & $\begin{array}{l}\text { Passaged, naturally tumor- } \\
\text { selective }\end{array}$ & Preclinical & 131 \\
\hline
\end{tabular}

$\mathrm{HSV}=$ herpes simplex virus; IL = interleukin; IRES internal ribosome entry sequence; $\mathrm{MV}=$ measle virus; NDV $=$ Newcastle disease virus; $\mathrm{PV}=$ poliovirus; $\mathrm{RIPO}=$ oncolytic poliovirus; $\mathrm{VSV}=$ vesicular stomatitis virus; $\mathrm{VV}=$ vaccinia virus. 


\section{CONCLUSIONS AND FUTURE OF OV THERAPY}

The study of viruses for glioma therapy has become increasingly popular within the past 2 decades, as more sophisticated genetic manipulations have led to the development of safer and more tumor-specific viruses. The safety of several of these tumor-targeted viruses have been confirmed by several phase I clinical trials for the HSVs G2079,13 and HSV1716, ${ }^{10,14,132}$ adenovirus ONYX$015,{ }^{11}$ as well as for the Reolysin reovirus trial, ${ }^{12}$ Newcastle disease virus vectors MTH-68/H, ${ }^{103,104}$ and NDVHUJ. ${ }^{105}$ Table 2 summarizes the different types of oncolytic viral vectors currently in preclinical studies and in phase I and phase II clinical trials for glioma therapy.

Several recent studies indicate that supplementing glioma treatment regimens incorporating chemotherapy or radiotherapy with viral therapy may lead to synergistic antitumor effects. Collectively, the clinically-proven safety of several of these viruses, along with their efficacy in preclinical studies and their evidence of improved tumor oncolysis when administered with standard treatments, support further investigation of these agents in the hope that they may develop into efficacious therapies for these recalcitrant tumors.

\section{REFERENCES}

1. De Pace NG. Sulla scomparsa di un enorme cancro vegetante del callo dell'utero senza cura chirurgica. Ginecologia (France) 1912; 9:82-88.

2. Huebner RJ, Rowe WP, Schatten WE, Smith RR, Thomas LB. Studies on the use of viruses in the treatment of carcinoma of the cervix. Cancer 1956;9:1211-1218.

3. Wheelock EF, Dingle JH. Observations on the repeated administration of viruses to a patient with acute leukemia. A preliminary report. N Engl J Med 1964;271:645-651.

4. Bluming AZ, Ziegler JL. Regression of Burkitt's lymphoma in association with measles infection. Lancet 1971;2:105-106.

5. Taqi AM, Abdurrahman MB, Yakubu AM, Fleming AF. Regression of Hodgkin's disease after measles. Lancet 1981;1:1112.

6. Asada T. Treatment of human cancer with mumps virus. Cancer 1974;34:1907-1928.

7. Okuno Y, Asada T, Yamanishi K, et al. Studies on the use of mumps virus for treatment of human cancer. Biken J 1978;21: 37-49.

8. Martuza RL, Malick A, Markert JM, Ruffner KL, Coen DM. Experimental therapy of human glioma by means of a genetically engineered virus mutant. Science 1991;252:854-856.

9. Markert JM, Medlock MD, Rabkin SD, et al. Conditionally replicating herpes simplex virus mutant, G207 for the treatment of malignant glioma: results of a phase I trial. Gene Ther 2000;7: 867-874.

10. Rampling R, Cruickshank G, Papanastassiou V, et al. Toxicity evaluation of replication-competent herpes simplex virus (ICP 34.5 null mutant 1716) in patients with recurrent malignant glioma. Gene Ther 2000;7:859-866.

11. Chiocca EA, Abbed KM, Tatter S, et al. A phase I open-label, dose-escalation, multi-institutional trial of injection with an E1BAttenuated adenovirus, ONYX-015, into the peritumoral region of recurrent malignant gliomas, in the adjuvant setting. Mol Ther 2004;10:958-966.

12. Forsyth P, Roldan G, George D, et al. A phase I trial of intratumoral administration of reovirus in patients with histo- logically confirmed recurrent malignant gliomas. Mol Ther 2008;16:627-632.

13. Markert JM, Liechty PG, Wang W, et al. Phase Ib trial of mutant herpes simplex virus G207 inoculated pre-and post-tumor resection for recurrent GBM. Mol Ther 2009;17:199-207.

14. Papanastassiou V, Rampling R, Fraser M, et al. The potential for efficacy of the modified (ICP $34.5(-)$ ) herpes simplex virus HSV1716 following intratumoural injection into human malignant glioma: a proof of principle study. Gene Ther 2002;9:398406.

15. Roizman B, Pellett PE. The family herpesviridae: a brief introduction. In: Knipe DM, Howley PM, eds. Fields Virology, 4th edit. Philadelphia: Lippincott Williams \& Wilkins, 2001:23812397.

16. Goldstein DJ, Weller SK. Herpes simplex virus type 1-induced ribonucleotide reductase activity is dispensable for virus growth and DNA synthesis: isolation and characterization of an ICP6 lacZ insertion mutant. J Virol 1988;62:196-205.

17. Goldstein DJ, Weller SK. Factor(s) present in herpes simplex virus type 1-infected cells can compensate for the loss of the large subunit of the viral ribonucleotide reductase: characterization of an ICP6 deletion mutant. Virology 1988;166:41-51.

18. Mineta T, Rabkin SD, Martuza RL. Treatment of malignant gliomas using ganciclovir-hypersensitive, ribonucleotide reductasedeficient herpes simplex viral mutant. Cancer Res 1994;54:39633966.

19. Coen DM, Goldstein DJ, Weller SK. Herpes simplex virus ribonucleotide reductase mutants are hypersensitive to acyclovir. Antimicrob Agents Chemother 1989;33:1395-1399.

20. He B, Gross M, Roizman B. The gamma(1)34.5 protein of herpes simplex virus 1 complexes with protein phosphatase 1 alpha to dephosphorylate the alpha subunit of the eukaryotic translation initiation factor 2 and preclude the shutoff of protein synthesis by double-stranded RNA-activated protein kinase. Proc Natl Acad Sci U S A 1997;94:843-848.

21. Chou J, Kern ER, Whitley RJ, Roizman B. Mapping of herpes simplex virus-1 neurovirulence to gamma 134.5, a gene nonessential for growth in culture. Science 1990;250:1262-1266.

22. Farassati F, Yang AD, Lee PW. Oncogenes in Ras signalling pathway dictate host-cell permissiveness to herpes simplex virus 1. Nat Cell Biol 2001;3:745-750.

23. Chou J, Roizman B. The gamma 1(34.5) gene of herpes simplex virus 1 precludes neuroblastoma cells from triggering total shutoff of protein synthesis characteristic of programed cell death in neuronal cells. Proc Natl Acad Sci U S A 1992;89:3266-3270.

24. Whitley RJ, Kern ER, Chatterjee S, Chou J, Roizman B. Replication, establishment of latency, and induced reactivation of herpes simplex virus gamma 134.5 deletion mutants in rodent models. J Clin Invest 1993;91:2837-2843.

25. Mineta T, Rabkin SD, Yazaki T, Hunter WD, Martuza RL. Attenuated multi-mutated herpes simplex virus-1 for the treatment of malignant gliomas. Nat Med 1995;1:938-943.

26. MacLean AR, ul-Fareed M, Robertson L, Harland J, Brown SM. Herpes simplex virus type 1 deletion variants 1714 and 1716 pinpoint neurovirulence-related sequences in Glasgow strain 17+ between immediate early gene 1 and the 'a' sequence. J Gen Virol 1991;72(Pt 3):631-639.

27. Sundaresan P, Hunter WD, Martuza RL, Rabkin SD. Attenuated, replication-competent herpes simplex virus type 1 mutant G207: safety evaluation in mice. J Virol 2000;74:3832-3841.

28. Hunter WD, Martuza RL, Feigenbaum F, et al. Attenuated, replication-competent herpes simplex virus type 1 mutant G207: safety evaluation of intracerebral injection in nonhuman primates. J Virol 1999;73:6319-6326.

29. Andreansky S, He B, van Cott J, et al. Treatment of intracranial gliomas in immunocompetent mice using herpes simplex viruses that express murine interleukins. Gene Ther 1998;5:121-130.

30. Parker JN, Gillespie GY, Love CE, Randall S, Whitley RJ, Markert JM. Engineered herpes simplex virus expressing IL-12 in the treatment of experimental murine brain tumors. Proc Natl Acad Sci U S A 2000;97:2208-2213. 
31. Chase M, Chung RY, Chiocca EA. An oncolytic viral mutant that delivers the CYP2B1 transgene and augments cyclophosphamide chemotherapy. Nat Biotechnol 1998;16:444-448.

32. Ichikawa T, Petros WP, Ludeman SM, et al. Intraneoplastic polymer-based delivery of cyclophosphamide for intratumoral bioconversion by a replicating oncolytic viral vector. Cancer Res 2001;61:864-868.

33. Wei MX, Tamiya T, Rhee RJ, Breakefield XO, Chiocca EA. Diffusible cytotoxic metabolites contribute to the in vitro bystander effect associated with the cyclophosphamide/cytochrome P450 2B1 cancer gene therapy paradigm. Clin Cancer Res 1995; 1:1171-1177.

34. Kambara H, Okano H, Chiocca EA, Saeki Y. An oncolytic HSV-1 mutant expressing ICP 34.5 under control of a nestin promoter increases survival of animals even when symptomatic from a brain tumor. Cancer Res 2005;65:2832-2839.

35. Glass M, Soling A, Messerle M. Tumor-specific activity of cellular regulatory elements is down-regulated upon insertion into the herpes simplex virus genome. J Neurovirol 2008:1-14.

36. Cassady KA. Human cytomegalovirus TRS1 and IRS1 gene products block the double-stranded-RNA-activated host protein shutoff response induced by herpes simplex virus type 1 infection. J Virol 2005;79:8707-8715.

37. Shah AC, Parker JN, Gillespie GY, et al. Enhanced antiglioma activity of chimeric HCMV/HSV-1 oncolytic viruses. Gene Ther 2007; 14:1045-1054.

38. Zhou G, Ye GJ, Debinski W, Roizman B. Engineered herpes simplex virus 1 is dependent on IL13Ralpha 2 receptor for cell entry and independent of glycoprotein $\mathrm{D}$ receptor interaction. Proc Natl Acad Sci U S A 2002;99:15124-15129.

39. Mintz A, Gibo DM, Slagle-Webb B, Christensen ND, Debinski W. IL-13Ralpha2 is a glioma-restricted receptor for interleukin13. Neoplasia 2002;4:388-399.

40. Zhou G, Roizman B. Characterization of a recombinant herpes simplex virus 1 designed to enter cells via the IL13Ralpha2 receptor of malignant glioma cells. J Virol 2005;79:5272-5277.

41. Zhou G, Roizman B. Construction and properties of a herpes simplex virus 1 designed to enter cells solely via the IL-13alpha2 receptor. Proc Natl Acad Sci U S A 2006;103:5508-5513.

42. Fu X, Meng F, Tao L, Jin A, Zhang X. A strict-late viral promoter is a strong tumor-specific promoter in the context of an oncolytic herpes simplex virus. Gene Ther 2003;10:1458-1464.

43. Kanai R, Tomita H, Hirose Y, et al. Augmented therapeutic efficacy of an oncolytic herpes simplex virus type 1 mutant expressing ICP 34.5 under the transcriptional control of musashi1 promoter in the treatment of malignant glioma. Hum Gene Ther 2007;18:63-73.

44. Weichselbaum RR, Kufe DW, Advani SJ, Roizman B. Molecular targeting of gene therapy and radiotherapy. Acta Oncol 2001;40: 735-738.

45. Advani SJ, Sibley GS, Song PY, et al. Enhancement of replication of genetically engineered herpes simplex viruses by ionizing radiation: a new paradigm for destruction of therapeutically intractable tumors. Gene Ther 1998;5:160-165.

46. Bradley JD, Kataoka Y, Advani S, et al. Ionizing radiation improves survival in mice bearing intracranial high- grade gliomas injected with genetically modified herpes simplex virus. Clin Cancer Res 1999;5:1517-1522.

47. Aghi M, Rabkin S, Martuza RL. Effect of chemotherapy-induced DNA repair on oncolytic herpes simplex viral replication. J Natl Cancer Inst 2006;98:38-50.

48. Rainov NG, Fels C, Droege JW, Schafer C, Kramm CM, Chou TC. Temozolomide enhances herpes simplex virus thymidine kinase/ganciclovir therapy of malignant glioma. Cancer Gene Ther 2001;8:662-668.

49. Hadjipanayis CG, Fellows-Mayle W, Deluca NA. Therapeutic efficacy of a herpes simplex virus with radiation or temozolomide for intracranial glioblastoma after convection-enhanced delivery. Mol Ther 2008;16:1783-1788.

50. Shenk TE. Adenoviridae: the viruses and their replication. In: Knipe DM, Howley PM, eds. Fields Virology, 4th edit. Philadelphia: Lippincott Williams \& Wilkins, 2001:2265-2300.

51. O'Shea CC, Johnson L, Bagus B, et al. Late viral RNA export, rather than p53 inactivation, determines ONYX-015 tumor selectivity. Cancer Cell 2004;6:611-623.

52. Geoerger B, Grill J, Opolon P, et al. Oncolytic activity of the E1B-55 kDa-deleted adenovirus ONYX-015 is independent of cellular p53 status in human malignant glioma xenografts. Cancer Res 2002;62:764-772.

53. Geoerger B, Grill J, Opolon P, et al. Potentiation of radiation therapy by the oncolytic adenovirus d11520 (ONYX-015) in human malignant glioma xenografts. Br J Cancer 2003;89:577-584.

54. Fueyo J, Gomez-Manzano C, Alemany R, et al. A mutant oncolytic adenovirus targeting the $\mathrm{Rb}$ pathway produces anti-glioma effect in vivo. Oncogene 2000;19:2-12.

55. Jiang H, Gomez-Manzano C, Alemany R, et al. Comparative effect of oncolytic adenoviruses with E1A-55 kDa or E1B-55 kDa deletions in malignant gliomas. Neoplasia 2005;7:48-56.

56. Gomez-Manzano C, Alonso MM, Yung WK, et al. Delta-24 increases the expression and activity of topoisomerase I and enhances the antiglioma effect of irinotecan. Clin Cancer Res 2006;12:556-562.

57. Geoerger B, Vassal G, Opolon P, et al. Oncolytic activity of p53-expressing conditionally replicative adenovirus AdDelta24p53 against human malignant glioma. Cancer Res 2004;64:57535759.

58. Idema S, Lamfers ML, van Beusechem VW, et al. AdDelta24 and the p53-expressing variant AdDelta24-p53 achieve potent antitumor activity in glioma when combined with radiotherapy. J Gene Med 2007;9:1046-1056.

59. Conrad C, Miller CR, Ji Y, et al. Delta24-hyCD adenovirus suppresses glioma growth in vivo by combining oncolysis and chemosensitization. Cancer Gene Ther 2005;12:284-294.

60. Lamfers ML, Gianni D, Tung $\mathrm{CH}$, et al. Tissue inhibitor of metalloproteinase-3 expression from an oncolytic adenovirus inhibits matrix metalloproteinase activity in vivo without affecting antitumor efficacy in malignant glioma. Cancer Res 2005;65: 9398-9405.

61. Fueyo J, Alemany R, Gomez-Manzano C, et al. Preclinical characterization of the antiglioma activity of a tropism-enhanced adenovirus targeted to the retinoblastoma pathway. J Natl Cancer Inst 2003;95:652-660.

62. Jiang H, Gomez-Manzano C, Aoki H, et al. Examination of the therapeutic potential of Delta-24-RGD in brain tumor stem cells: role of autophagic cell death. J Natl Cancer Inst 2007;99:1410 1414.

63. Gomez-Manzano C, Balague C, Alemany R, et al. A novel E1AE1B mutant adenovirus induces glioma regression in vivo. Oncogene 2004;23:1821-1828.

64. Ulasov IV, Tyler MA, Rivera AA, Nettlebeck DM, Douglas JT, Lesniak MS. Evaluation of E1A double mutant oncolytic adenovectors in anti-glioma gene therapy. J Med Virol 2008;80: $1595-1603$.

65. Alonso MM, Cascallo M, Gomez-Manzano C, et al. ICOVIR-5 shows E2F1 addiction and potent antiglioma effect in vivo. Cancer Res 2007;67:8255-8263.

66. Ulasov IV, Rivera AA, Nettelbeck DM, et al. An oncolytic adenoviral vector carrying the tyrosinase promoter for glioma gene therapy. Int J Oncol 2007;31:1177-1185.

67. Nandi S, Ulasov IV, Tyler MA, et al. Low-dose radiation enhances survivin-mediated virotherapy against malignant glioma stem cells. Cancer Res 2008;68:5778-5784.

68. Sonabend AM, Ulasov IV, Han Y, et al. Biodistribution of an oncolytic adenovirus after intracranial injection in permissive animals: a comparative study of Syrian hamsters and cotton rats. Cancer Gene Ther 2009;16:362-372.

69. Ulasov IV, Rivera AA, Sonabend AM, et al. Comparative evaluation of survivin, midkine and CXCR4 promoters for transcriptional targeting of glioma gene therapy. Cancer Biol Ther 2007; 6:679-685.

70. Ulasov IV, Zhu ZB, Tyler MA, et al. Survivin-driven and fibermodified oncolytic adenovirus exhibits potent antitumor activity in established intracranial glioma. Hum Gene Ther 2007; 18:589602 . 
71. Van Houdt WJ, Haviv YS, Lu B, et al. The human survivin promoter: a novel transcriptional targeting strategy for treatment of glioma. J Neurosurg 2006;104:583-592.

72. Zhu ZB, Makhija SK, Lu B, et al. Incorporating the survivin promoter in an infectivity enhanced CRAd-analysis of oncolysis and anti-tumor effects in vitro and in vivo. Int J Oncol 2005;27: 237-246.

73. Bieler A, Mantwill K, Dravits T, et al. Novel three-pronged strategy to enhance cancer cell killing in glioblastoma cell lines: histone deacetylase inhibitor, chemotherapy, and oncolytic adenovirus d1520. Hum Gene Ther 2006;17:55-70.

74. Bieler A, Mantwill K, Holzmuller R, et al. Impact of radiation therapy on the oncolytic adenovirus dl520: implications on the treatment of glioblastoma. Radiother Oncol 2008;86:419-427.

75. Post DE, Devi NS, Li Z, et al. Cancer therapy with a replicating oncolytic adenovirus targeting the hypoxic microenvironment of tumors. Clin Cancer Res 2004;10:8603-8612.

76. Horst M, Brouwer E, Verwijnen S, et al. Targeting malignant gliomas with a glial fibrillary acidic protein (GFAP)-selective oncolytic adenovirus. J Gene Med 2007;9:1071-1079.

77. Ito H, Aoki H, Kuhnel F, et al. Autophagic cell death of malignant glioma cells induced by a conditionally replicating adenovirus. J Natl Cancer Inst 2006;98:625-636.

78. Yokoyama T, Iwado E, Kondo Y, et al. Autophagy-inducing agents augment the antitumor effect of telerase-selve oncolytic adenovirus OBP-405 on glioblastoma cells. Gene Ther 2008;15: 1233-1239.

79. Hoffmann D, Meyer B, Wildner O. Improved glioblastoma treatment with Ad5/35 fiber chimeric conditionally replicating adenoviruses. J Gene Med 2007;9:764-778.

80. Hoffmann D, Wildner O. Comparison of herpes simplex virusand conditionally replicative adenovirus-based vectors for glioblastoma treatment. Cancer Gene Ther 2007;14:627-639.

81. Wohlfahrt ME, Beard BC, Lieber A, Kiem HP. A capsid-modified, conditionally replicating oncolytic adenovirus vector expressing TRAIL Leads to enhanced cancer cell killing in human glioblastoma models. Cancer Res 2007;67:8783-8790.

82. Nanda D, Vogels R, Havenga M, Avezaat CJ, Bout A, Smitt PS. Treatment of malignant gliomas with a replicating adenoviral vector expressing herpes simplex virus-thymidine kinase. Cancer Res 2001;61:8743-8750.

83. Nibert ML, Schiff LA. Reoviruses and their replication. In: Knipe DM, Howley PM, eds. Fields Virology, 4th edit. Philadelphia: Lippincott, Williams \& Wilkins, 2001.

84. Nishikawa R, Ji XD, Harmon RC, et al. A mutant epidermal growth factor receptor common in human glioma confers enhanced tumorigenicity. Proc Natl Acad Sci U S A 1994;91:77277731.

85. Nister M, Claesson-Welsh L, Eriksson A, Heldin CH, Westermark B. Differential expression of platelet-derived growth factor receptors in human malignant glioma cell lines. J Biol Chem 1991;266:16755-16763.

86. Wilcox ME, Yang W, Senger D, et al. Reovirus as an oncolytic agent against experimental human malignant gliomas. J Natl Cancer Inst 2001;93:903-912.

87. Coffey MC, Strong JE, Forsyth PA, Lee PW. Reovirus therapy of tumors with activated Ras pathway. Science 1998;282:13321334.

88. Yang WQ, Senger D, Muzik H, et al. Reovirus prolongs survival and reduces the frequency of spinal and leptomeningeal metastases from medulloblastoma. Cancer Res 2003;63:3162-3172.

89. Yang WQ, Lun X, Palmer CA, et al. Efficacy and safety evaluation of human reovirus type 3 in immunocompetent animals: racine and nonhuman primates. Clin Cancer Res 2004;10:85618576.

90. Alexander DJ, Allan WH. Newcastle disease virus pathotypes. Avian Pathol 1974;3:269-278.

91. Schirrmacher V, Griesbach A, Ahlert T. Antitumor effects of Newcastle disease virus in vivo: local versus systemic effects. Int J Oncol 2001;18:945-952.

92. Cassel WA, Garrett RE. Newcastle disease virus as an antineoplastic agent. Cancer 1965;18:863-868.
93. Reichard KW, Lorence RM, Cascino CJ, et al. Newcastle disease virus selectively kills human tumor cells. J Surg Res 1992;52: 448-453.

94. Lorence RM, Reichard KW, Katubig BB, et al. Complete regression of human neuroblastoma xenografts in athymic mice after local Newcastle disease virus therapy. J Natl Cancer Inst 1994; $86: 1228-1233$.

95. Lorence RM, Katubig BB, Reichard KW, et al. Complete regression of human fibrosarcoma xenografts after local Newcastle disease virus therapy. Cancer Res 1994;54:6017-6021.

96. Phuangsab A, Lorence RM, Reichard KW, Peeples ME, Walter RJ. Newcastle disease virus therapy of human tumor xenografts: antitumor effects of local or systemic administration. Cancer Lett 2001;172:27-36.

97. Pecora AL, Rizvi N, Cohen GI, et al. Phase I trial of intravenous administration of PV701, an oncolytic virus, in patients with advanced solid cancers. J Clin Oncol 2002;20:2251-2266.

98. Laurie SA, Bell JC, Atkins HL, et al. A phase 1 clinical study of intravenous administration of PV701, an oncolytic virus, using two-step desensitization. Clin Cancer Res 2006;12:2555-2562.

99. Lorence RM, Roberts MS, O'Neil JD, et al. Phase 1 clinical experience using intravenous administration of PV701, an oncolytic Newcastle disease virus. Curr Cancer Drug Targets 2007;7: $157-167$.

100. Csatary LK. Viruses in the treatment of cancer. Lancet 1971;2: 825.

101. Csatary LK, Bakacs T. Use of Newcastle disease virus vaccine (MTH-68/H) in a patient with high-grade glioblastoma. JAMA 1999;281:1588-1589.

102. Csatary LK, Moss RW, Beuth J, Torocsik B, Szeberenyi J, Bakacs T. Beneficial treatment of patients with advanced cancer using a Newcastle disease virus vaccine (MTH-68/H). Anticancer Res 1999;19:635-638.

103. Csatary LK, Gosztonyi G, Szeberenyi J, et al. MTH-68/H oncolytic viral treatment in human high-grade gliomas. J Neurooncol 2004;67:83-93.

104. Wagner S, Csatary CM, Gosztonyi G, et al. Combined treatment of pediatric high-grade glioma with the oncolytic viral strain MTH-68/H and oral valproic acid. APMIS 2006;114:731-743.

105. Freeman AI, Zakay-Rones Z, Gomori JM, et al. Phase I/II trial of intravenous NDV-HUJ oncolytic virus in recurrent glioblastoma multiforme. Mol Ther 2006;13:221-228.

106. Zulkifli MM, Ibrahim R, Ali AM, et al. Newcastle diseases virus strain V4UPM displayed oncolytic ability against experimental human malignant glioma. Neurol Res 2008.

107. Anderson BD, Nakamura T, Russell SJ, Peng KW. High CD46 receptor density determines preferential killing of tumor cells by oncolytic measles virus. Cancer Res 2004;64:4919-4926.

108. Phuong LK, Allen C, Peng KW, et al. Use of a vaccine strain of measles virus genetically engineered to produce carcinoembryonic antigen as a novel therapeutic agent against glioblastoma multiforme. Cancer Res 2003;63:2462-2469.

109. Myers R, Harvey M, Kaufmann TJ, et al. Toxicology study of repeat intracerebral administration of a measles virus derivative producing carcinoembryonic antigen in rhesus macaques in support of a phase I/II clinical trial for patients with recurrent gliomas. Hum Gene Ther 2008;19:690-698.

110. Wallack MK, Sivanandham M, Balch CM, et al. Surgical adjuvant active specific immunotherapy for patients with stage III melanoma: the final analysis of data from a phase III, randomized, double-blind, multicenter vaccinia melanoma oncolysate trial. J Am Coll Surg 1998;187:69-77; discussion 77-69.

111. Buller RM, Smith GL, Cremer K, Notkins AL, Moss B. Decreased virulence of recombinant vaccinia virus expression vectors is associated with a thymidine kinase-negative phenotype. Nature 1985;317:813-815.

112. Puhlmann M, Gnant M, Brown CK, Alexander HR, Bartlett DL. Thymidine kinase-deleted vaccinia virus expressing purine nucleoside phosphorylase as a vector for tumor-directed gene therapy. Hum Gene Ther 1999;10:649-657.

113. Timiryasova TM, Chen B, Haghighat P, Fodor I. Vaccinia virusmediated expression of wild-type p53 suppresses glioma cell growth and induces apoptosis. Int J Oncol 1999;14:845-854. 
114. Gridley DS, Andres ML, Li J, Timiryasova T, Chen B, Fodor I. Evaluation of radiation effects against $\mathrm{C} 6$ glioma in combination with vaccinia virus-p53 gene therapy. Int J Oncol 1998;13:10931098.

115. Chen B, Timiryasova TM, Andres ML, et al. Evaluation of combined vaccinia virus-mediated antitumor gene therapy with $\mathrm{p} 53$, IL-2, and IL-12 in a glioma model. Cancer Gene Ther 2000;7: $1437-1447$.

116. Chen B, Timiryasova TM, Haghighat $P$, et al. Low-dose vaccinia virus-mediated cytokine gene therapy of glioma. J Immunother 2001;24:46-57.

117. McFadden G. Poxvirus tropism. Nat Rev Microbiol 2005;3:201213.

118. Lun X, Yang W, Alain T, et al. Myxoma virus is a novel oncolytic virus with significant antitumor activity against experimental human gliomas. Cancer Res 2005;65:9982-9990.

119. Lun XQ, Zhou H, Alain T, et al. Targeting human medulloblastoma: oncolytic virotherapy with myxoma virus is enhanced by rapamycin. Cancer Res 2007;67:8818-8827.

120. Gromeier M, Alexander L, Wimmer E. Internal ribosomal entry site substitution eliminates neurovirulence in intergeneric poliovirus recombinants. Proc Natl Acad Sci U S A 1996;93:23702375.

121. Gromeier M, Bossert B, Arita M, Nomoto A, Wimmer E. Dual stem loops within the poliovirus internal ribosomal entry site control neurovirulence. J Virol 1999;73:958-964.

122. Gromeier M, Lachmann S, Rosenfeld MR, Gutin PH, Wimmer E. Intergeneric poliovirus recombinants for the treatment of malignant glioma. Proc Natl Acad Sci U S A 2000;97:6803-6808.

123. Merrill MK, Bernhardt G, Sampson JH, Wikstrand CJ, Bigner DD, Gromeier M. Poliovirus receptor CD155-targeted oncolysis of glioma. Neuro Oncol 2004;6:208-217.
124. Dobrikova EY, Broadt T, Poiley-Nelson J, et al. Recombinant oncolytic poliovirus eliminates glioma in vivo without genetic adaptation to a pathogenic phenotype. Mol Ther 2008;16:18651872.

125. Ansardi DC, Porter DC, Morrow CD. Complementation of a poliovirus defective genome by a recombinant vaccinia virus which provides poliovirus P1 capsid precursor in trans. J Virol 1993;67:3684-3690.

126. Hagino-Yamagishi K, Nomoto A. In vitro construction of poliovirus defective interfering particles. J Virol 1989;63:5386-5392.

127. Bledsoe AW, Gillespie GY, Morrow CD. Targeted foreign gene expression in spinal cord neurons using poliovirus replicons. J Neurovirol 2000;6:95-105.

128. Ansardi DC, Porter DC, Jackson CA, Gillespie GY, Morrow CD. RNA replicons derived from poliovirus are directly oncolytic for human tumor cells of diverse origins. Cancer Res 2001;61:8470 8479.

129. Rose JK, Whitt MA. Rhabdoviridae: The viruses and their replication. In: Knipe DM, Howley PM, eds. Fields Virology, 4th edit. Philadelphia: Lippincott, Williams and Wilkens, 2001:12211244.

130. Wollmann G, Tattersall P, van den Pol AN. Targeting human glioblastoma cells: comparison of nine viruses with oncolytic potential. J Virol 2005;79:6005-6022.

131. Ozduman K, Wollmann G, Piepmeier JM, van den Pol AN. Systemic vesicular stomatitis virus selectively destroys multifocal glioma and metastatic carcinoma in brain. J Neurosci 2008;28: 1882-1893.

132. Harrow S, Papanastassiou V, Harland J, et al. HSV1716 injection into the brain adjacent to tumour following surgical resection of high-grade glioma: safety data and long-term survival. Gene Ther 2004;11:1648-1658. 